\title{
FOUCAULT, NEOLIBERALISMO E EDUCAÇÃO: UMA ANÁLISE DAS PRÁTICAS DE MEMORIZAÇÃO NO ENSINO DE MATEMÁTICA
}

\author{
FOUCAULT, NEOLIBERALISM AND EDUCATION: AN ANALYSIS OF MEMORIZATION \\ PRACTICES IN THE TEACHING OF MATHEMATICS
}

https://orcid.org/0000-0002-0442-6645 Alice Stephanie Tapia Sartori ${ }^{\mathrm{A}}$ (D) https://orcid.org/0000-0002-8608-5855 Claudia Glavam Duarte ${ }^{\mathrm{B}}$

\author{
${ }^{\text {A }}$ Universidade Federal do Rio Grande do Sul (UFRS), Porto Alegre, RS, Brasil \\ ${ }^{\text {B } U n i v e r s i d a d e ~ F e d e r a l ~ d o ~ R i o ~ G r a n d e ~ d o ~ S u l ~(U F R S), ~ P o r t o ~ A l e g r e, ~ R S, ~ B r a s i l ~}$ \\ Recebido em: 21052020 | Aceito em: 31052021 \\ Correspondência: Alice (alice.stephanie.ts@gmail.com); Claudia (claudiaglavam@hotmail.com)
}

\section{Resumo}

Este artigo aborda algumas ressonâncias do pensamento do filósofo Michel Foucault no campo educativo, especificamente na Educação Matemática, a partir de um recorte de uma Tese de doutorado que teve como problema de pesquisa a seguinte questão: Como as práticas de memorização na Educação Matemática foram sendo reconfiguradas nos discursos da Revista Nova Escola? As ferramentas metodológicas utilizadas advêm da análise do discurso na perspectiva foucaultiana, lentes com as quais analisamos exemplares desta Revista publicados entre 1986 e 2015. Constatamos que, ao negarem a memorização mecanizada, as reportagens enfatizam a formação de um aluno crítico, criativo, autônomo e empreendedor de si, características necessárias ao sujeito constituído na lógica do neoliberalismo.

Palavras-chave: Educação Matemática; Neoliberalismo; Foucault; Memorização.

\section{Abstract}

This article approachs some resonances of the philosopher Michel Foucault's thought in the educational field, specifically in Mathematics Education, from a doctoral thesis that had the following question as research problem: How were the memorization practices in Mathematics Education become reconfiguring in the discourses of Revista Nova Escola? The methodological tools used come from discourse analysis in the Foucauldian perspective, lenses with which we analyzed editions of this Magazine published between 1986 and 2015. We found that, by denying mechanized memorization, the reports emphasize the formation of a student critical, creative, autonomous and entrepreneur of the self, characteristics necessary to the constituted subject in the logic of neoliberalism.

Keywords: Mathematics Education; Neoliberalism; Foucault; Memorization. 


\section{Introdução}

Neste artigo, temos como objetivo discutir algumas ressonâncias do pensamento do filósofo Michel Foucault no campo educativo, especificamente no campo da Educação Matemática, a partir de um recorte de uma Tese de doutorado que teve como problema de pesquisa a seguinte questão: Como as práticas de memorização na Educação Matemática foram sendo reconfiguradas nos discursos da Revista Nova Escola? Uma das reconfigurações enfatizadas nesse trabalho, a qual será explorada aqui, diz respeito à constituição do sujeito necessário à lógica neoliberal.

Cabe destacarmos que se trata de uma pesquisa dentro do campo da Educação Matemática, porém nos referimos especificamente ao ensino de matemática na escola, visto que a discussão recai sobre as práticas pedagógicas de professores, ou seja, práticas de ensino desta disciplina, sendo que a análise versa sobre os discursos nesse campo de saber. Nesse sentido, situamos duas áreas distintas, que inclusive, têm acirrado suas divergências como campos de pesquisa em Educação Matemática e no Ensino de Matemática. No entanto, estamos considerando o ensino da matemática escolar como uma das vertentes de discussões dentro do campo da Educação Matemática.

Levar em conta as reconfigurações das práticas de memorização no ensino de matemática requer considerarmos as mudanças da escola como um todo, e especialmente suas relações com a sociedade. A escola é um espaço privilegiado de invenção, aplicação e transmissão de técnicas sustentadas pelas teorias pedagógicas. Assim, consideramos pertinente apontar o modo como a escola é compreendida quando exploramos as possibilidades das teorizações de Foucault para pensar a Educação Matemática. Nesta perspectiva, a escola pode ser considerada como uma das principais instituições sociais encarregadas de formar sujeitos, pois é também nesse lugar que as novas tecnologias de governo são inventadas, aplicadas e disseminadas. Em consonância com o pensamento do filósofo, consideramos que as práticas pedagógicas, bem como tantas outras práticas presentes na sociedade, contribuem para a produção do sujeito neoliberal exigido pela sociedade contemporânea.

No entanto, cabe ressaltar que na perspectiva foucaultiana a função da escola não é propiciar o desenvolvimento de um sujeito que é dado como natural, ou que ela seja um caminho para garantir a racionalidade e a liberdade. Além disso, a escola não deve ser “analisada a partir de princípios intelectuais e morais tomados a priori - um tipo de ideologismo fundado nas filosofias da consciência" (VEIGA-NETO, 2000, p. 180). Outra 
precaução elencada por Veiga-Neto (2000) é a importância de avaliarmos as relações entre a escola e os contextos econômico, político, social e cultural como uma relação de imanência, pois ao mesmo tempo em que ponderamos as implicações das práticas escolares na sociedade, devemos assumir que a escola é produzida por ela. Não se trata ainda de julgar as práticas escolares de um determinado momento como adequadas ou não, pois entendemos que elas são efeitos de verdades que fazem parte de momentos historicamente distintos. Ao considerar a positividade do poder na escola, por exemplo, não se está fazendo uma defesa moral do poder, mas apontando sua produtividade.

Neste referencial, fazer uso de algumas ferramentas foucaultianas para investigar a escola significa, dentre outras possibilidades, problematizar as metanarrativas, as verdades que se pretendem universais, que perpassam os discursos educacionais. Isto pode ser feito a partir de questionamentos como: Que sujeito a maquinaria escolar estava interessada em fabricar na modernidade? Quais as funções da escola na contemporaneidade? Nestes contextos, como a Educação Matemática era/é mobilizada para colocar em prática estratégias de fabricação de subjetividades? Pretendemos percorrer estas questões compreendendo a Educação Matemática como sendo uma das engrenagens desta maquinaria, dando visibilidade a algumas condições de possibilidade para a instauração de verdades nesse campo de saber.

Se pensarmos na profusão destas verdades que operam a partir da Educação Matemática, podemos inferir que a memorização, a repetição e o decorar por décadas foram aspectos enfatizados por docentes e pesquisadores. Em discursos atuais observamos divergências sobre a importância ou não de memorizar os conteúdos ou fórmulas matemáticas. No entanto, para além de considerar as técnicas de memorização como válidas ou não, cabe-nos um exercício de problematização destas práticas em diferentes épocas, observando as rupturas pelas quais passou o ensino de matemática e identificando quais mecanismos agem sobre os corpos a fim de subjetivá-los.

Especificamente neste artigo, atentamos para a emergência e estabelecimento de uma forma de governamento advinda do neoliberalismo, a qual Foucault elucidou em seus últimos escritos. Assim, seguiremos algumas pistas teóricas e metodológicas das análises históricas realizadas pelo filósofo, pois possibilitam outros modos de olhar para as práticas de memorização, buscando identificar alguns possíveis efeitos destas práticas para a constituição de subjetividades discentes.

\section{Ferramentas Metodológicas}


Nossa opção analítica recai sobre o caráter discursivo da Revista Nova Escola, pois a consideramos um veículo atuante e abrangente de difusão de ideias pedagógicas no Brasil, sendo uma "peça-chave para a compreensão da mecânica geral do governamento docente na atualidade" (AQUINO, 2013, p. 206). Ademais, nesta Revista circulam verdades no campo da Educação Matemática, especialmente veiculadas por especialistas portadores de uma ampla visibilidade na mídia educativa. Com efeito, as propostas didáticas sugeridas pelas edições da Revista são atravessadas também por estas verdades, culminando com a difusão de modelos ideais de escola, de práticas pedagógicas e de subjetividades docentes e discentes.

Desde 1986, quando da publicação do primeiro exemplar da Nova Escola, a Revista expressa as principais mudanças no meio educacional, em suas reformas, teorias, leis e concepções pedagógicas. Além de considerá-la como elemento fundamental para uma leitura da docência, conforme assinala Aquino (2013), é significativo ainda dizer que avaliamos a Revista Nova Escola “apenas como um lugar de inscrição de discursos que acabaram por instituir modos de se pensar e agir" nesse campo de saber (DUARTE, 2009, p. 48).

$\mathrm{Na}$ Tese, de modo geral, foram analisados 235 exemplares da Revista, publicados entre 1986 e 2015, e deles foram extraídos os excertos que posteriormente formaram o corpus de análise da pesquisa. Especialmente neste artigo, recorremos à 20 excertos extraídos desse montante, o que corresponde à 17 revistas selecionadas.

Como olhamos para esse conjunto de elementos nas Revistas que nos conduzem ao objeto a ser estudado? Quais as lentes que nos permitem enxergar esses elementos e não outros? Segundo entendimento amplamente compartilhado, difundido por diversos autores e comentadores de Foucault, as teorizações elaboradas pelo filósofo nos fornecem ferramentas tanto teóricas quanto metodológicas, as quais procuramos explanar aqui de modo sucinto.

As proposições sobre a análise do discurso são constituídas por diversos conceitos, como os de enunciado, formação discursiva, história, dispositivo, sujeito, acontecimento, dentre outros, e a própria concepção de discurso, entendido como:

[...] um conjunto de enunciados, na medida em que se apoiem na mesma formação discursiva; ele não forma uma unidade retórica ou formal, indefinidamente repetível e cujo aparecimento ou utilização poderíamos assinalar (e explicar, se for o caso) na história; é constituído de um número limitado de enunciados para os quais podemos definir um conjunto de condições de existência (FOUCAULT, 2008a, p. 132). 
Para o filósofo, um enunciado define-se pela condição de existência a partir de unidades como frases, proposições e atos de linguagem, mas não se confunde com esses elementos, pois, além deles, o enunciado é marcado por suas singularidades históricas. O termo enunciado é utilizado, além de outros aspectos, para diferenciá-lo do todo, dos conjuntos de discursos. Os enunciados são estabelecidos ainda a partir de enunciações. Uma enunciação se expressa sempre que um conjunto de signos é emitido, e é também um acontecimento, mas que não se repete, ao contrário do enunciado. Um enunciado pode ser composto por múltiplas enunciações. Como explicou Foucault (2008a), quando uma pessoa diz algo, podemos tomar esta fala como uma enunciação. Se outra pessoa diz o mesmo e ao mesmo tempo, avaliamos que existem duas enunciações, o que expressa sua singularidade. De tal modo, para uma investigação histórica, pode-se analisar enunciações que produzem enunciados naturalizados como verdades em diferentes épocas.

O discurso da Educação Matemática, por exemplo, pode ser constituído por diversos enunciados que foram se reconfigurando com o passar do tempo, tornando-se verdades em uma época e não em outras. Incluem-se aí os enunciados referentes à memorização e suas derivações e sentidos atribuídos pela Revista. Assim, os enunciados visualizados nas Revistas emergem de enunciações como as falas dos sujeitos que compõem o espaço escolar, os relatos de práticas pedagógicas, as sugestões de pesquisadores na área, dentre outras.

Elegendo Foucault como nosso interlocutor teórico, pretendemos evidenciar nas Revistas as enunciações a respeito das práticas de memorização em diferentes épocas, e dar atenção às subjetividades que estavam/estão sendo produzidas e disponibilizadas, uma vez que nesta perspectiva, existe uma relação entre os discursos e a formação de subjetividades. Este trabalho analisa os enunciados que atravessam o campo da Educação Matemática por meio das Revistas, entendendo-os a partir de um tempo, um lugar e uma positividade concreta. Tal empreendimento se configura como um modo de interrogar singularidades marcantes da identidade do sujeito, atendendo a sua provisoriedade histórica.

Tal problemática tem relevância, pois um ponto essencial da filosofia foucaultiana é a problematização do sujeito como portador de uma essência, pois para ele, o sujeito é exterioridade e superfície de inscrição, ele é um efeito. Deste modo, o referencial teórico que aqui nos apropriamos possui estreita ligação com o referencial metodológico.

\section{Neoliberalismo e Educação: Teorizações foucaultianas}


O que a problematização foucaultiana a respeito do neoliberalismo pode acrescentar ao campo da Educação Matemática? Primeiramente, para compreender o liberalismo e o neoliberalismo em termos foucaultianos é preciso entendê-los não exclusivamente como fases históricas, como filosofias políticas ou sistemas econômicos, mas como formas de governo, que produzem sujeitos para atenderem às suas demandas. O que interessa ao filósofo no tema do neoliberalismo são as reverberações desta lógica do mercado nas questões políticas, éticas, filosóficas, etc. Segundo Lagasnerie (2013), alguns teóricos consideram que Foucault foi um aliado do neoliberalismo, porém, antes disso, cabe-nos analisar os tensionamentos que suas reflexões ocasionaram nas teorias neoliberais e entendê-las como uma grade de inteligibilidade para compreensão da sociedade.

Para Foucault, o neoliberalismo não é uma doutrina puramente econômica, afastada de qualquer vínculo com o privado, o que o distancia de um entendimento comum de que o neoliberalismo se resume ao Estado mínimo ou que tem a privatização como princípio básico. Esse é um aspecto singular na análise de Foucault, já que para ele o neoliberalismo implica também na produção de subjetividades por meio daquilo que não se considerava econômico. Baseado nesta visão, ele trata de acontecimentos políticos do liberalismo no século XVIII e da emergência do neoliberalismo no século XX.

Em seu curso ministrado no Collège de France em 1979, o qual posteriormente deu origem ao livro intitulado Nascimento da Biopolítica (2008b), Foucault problematiza o neoliberalismo buscando inverter o procedimento usual com o qual o capitalismo como sistema é compreendido. Na aula ministrada em 10 de janeiro de 1979, ele retoma uma crítica das concepções universais como, por exemplo, as de Estado, povo, soberania, sociedade civil, que permeiam as análises filosóficas e políticas em torno da governamentalidade neoliberal. Recusando alguns tipos de análises políticas, Foucault parte dos universais para pensá-los como grade de inteligibilidade das práticas, partindo, portanto, das práticas concretas ao invés dos conceitos naturalizados. Assim, o liberalismo e o neoliberalismo deixam de ser entendidos como uma extensão do Estado sobre a sociedade, o que caracteriza a dimensão política pela qual Foucault traça seus estudos.

A racionalidade liberal emergiu no século XVIII e seu regime de verdade baseou-se nas trocas, já que a liberdade é concebida como condição natural do mercado, limitando, assim, as ações governamentais do Estado. No contexto da troca, o que sustentava o liberalismo era a produção de bens comercializáveis, o que de certa forma esteve imbricado ao surgimento do capitalismo industrial no século XVIII. No protótipo do capitalismo industrial é o trabalho fabril 
que ganha ênfase, e outros setores acabam passando por modificações, como é o caso da mecanização da agricultura.

Com o liberalismo em vigor, existia uma fronteira entre o econômico e o político, o contrário do que ocorre com o advento do neoliberalismo, em que a racionalidade política é subordinada à economia, pois o Estado passa a governar a partir da lógica do mercado. A racionalidade política também fica condicionada à racionalidade de mercado, assim "o Estado é colocado sob a vigilância do mercado, ele deve governar não apenas para o mercado, mas também em função do que dita a lógica de mercado" (LAGASNERIE, 2013, p. 48). Nesse ponto há uma divergência com o liberalismo em que "era possível recortar, instaurar um espaço livre que seria o do mercado", já que para o neoliberalismo interessa regular o poder político por meio da economia. Portanto, retomando a argumentação foucaultiana, tal aspecto é caro ao entendimento do neoliberalismo visto que suas práticas exercem um papel moderador na sociedade de forma global. Nas palavras do filósofo, o neoliberalismo

tem de intervir sobre a própria sociedade em sua trama e em sua espessura. No fundo, ele tem de intervir nessa sociedade para que os mecanismos concorrenciais, a cada instante e em cada ponto da espessura social, possam ter o papel de reguladores - e é nisso que a sua intervenção vai possibilitar o que é o seu objetivo: a constituição de um regulador de mercado geral da sociedade (FOUCAULT, 2008b, p. 199).

Estas teorizações não afirmam que ocorra uma diminuição do papel do Estado ou seu retrocesso, como é geralmente entendido. O que ocorre é uma reinvenção de técnicas de governo para inserir o Estado na lógica da empresa. Ao explicitar as formações empresariais que se expandem no tecido social, Foucault (2008b) afirma que a concepção de empresa se amplia, não ficando restrita ao entendimento das grandes empresas de escalas nacionais e internacionais ou do Estado. Tal concepção passa a ser generalizada e multiplicada em outros âmbitos: "o que é a propriedade privada, senão uma empresa? O que é uma casa individual, senão uma empresa? O que é a gestão dessas pequenas comunidades de vizinhança [...], senão outras formas de empresa?" (Ibidem, p. 203). Assim, todas as formas de conduta se resumem na expansão e generalização da forma empresarial. Tal característica assume um individualismo em que a vida de cada um é moldada para ser uma espécie de empresa.

Assim, para Foucault (2008b), o neoliberalismo está vinculado a uma arte de governar e os sujeitos passam a ser constituídos a partir da racionalidade do mercado: "o essencial do projeto neoliberal consiste em instituir uma verdadeira "mercadização" da sociedade" 
(LAGASNERIE, 2013, p. 45), é preciso implantar "uma verdadeira "política da concorrência", destinada à difusão generalizada da forma-mercado" (Ibidem, p. 47).

A crise do liberalismo e a ascensão do neoliberalismo ocorreram no século XX mais propriamente por consequência de crises como a de 1929, da Segunda Guerra, das políticas keynesianas, dentre outros fatores, conforme pontua Saraiva (2015). Em meados de 1970 as teorias do neoliberalismo começam a surtir efeito, deslocando a ênfase do mercado das trocas para a competição. A liberdade instituída no comércio vai sendo substituída pela concorrência das empresas. Enquanto as trocas previam igualdade, a concorrência assume a suposta desigualdade em suas relações.

O indivíduo, nesta lógica neoliberal, é o seu próprio capital e empreendedor de si mesmo, pois "as análises mercadológicas estendem-se a relações não mercantis. O mercado passa a recobrir virtualmente toda a vida humana" (SARAIVA, 2015, p. 62). Deste modo, a vida do sujeito estará totalmente associada a sua "carreira", é esse o sujeito que precisa ser produzido.

Outro caminho situado por Foucault (2008b) para análise do liberalismo e do neoliberalismo é a teoria do Capital Humano. Todas as esferas da vida do indivíduo convergem para a produção deste capital, de modo que se torna incessante a busca pela resposta da questão: "Em que este ou aquele tipo de estímulo, esta ou aquela forma de vida, esta ou aquela relação com os pais, os adultos, os outros, em que tudo isso vai poder se cristalizar em capital humano?" (FOUCAULT, 2008b, p. 316).

O filósofo aponta que o homo oeconomicus, parceiro de troca, será substituído pelo homo oeconomicus, empresário de si, sendo ele mesmo seu próprio capital, seu produtor, sua fonte de renda. Há uma reativação da ideia do homo oeconomicus, que no neoliberalismo não é o parceiro de trocas, mas aquele que acredita ser portador de seu próprio capital. Na medida em que é produtor, o sujeito é também consumidor. No entanto,

não se deve acreditar que o consumo consiste em simplesmente ser, num processo de troca, alguém que compra e faz uma troca monetária para obter um certo número de produtos. O homem do consumo, na medida em que consome, é um produtor. Produz o quê? Pois bem, produz simplesmente sua própria satisfação (FOUCAULT, 2008b, p. 311).

Assim, o consumo é entendido por esse filósofo como uma atividade empresarial sendo que o produto é a satisfação do sujeito, constituído pelas múltiplas relações engendradas para além da economia. Com estas mudanças no cenário produtivo, a concorrência é cada vez mais excitada e a inovação torna-se palavra de ordem, caraterística que faz a criação estar à frente da 
produção. A invenção passa a ser uma regra, até mesmo para as indústrias que não deixam de ser motor de desenvolvimento, mas devem ser indústrias de inovações e não só de reprodução. Segundo Saraiva (2012, p. 141)

a grande transformação operada do liberalismo para o neoliberalismo seria o deslocamento do seu princípio de inteligibilidade: enquanto o liberalismo constituía-se a partir da noção de trocas, o neoliberalismo se constitui apoiado principalmente na noção de competição, justamente o que coloca a inovação em destaque.

Esta nova forma de governo neoliberal que tem interesse em capturar a liberdade, produz um sujeito competitivo, competente e seguro para fazer as próprias escolhas. Nesse ponto, a escola que atua como lugar privilegiado para a formação de um sujeito dono de suas próprias decisões, sendo autônomo e empreendedor de si, passa a se adequar às normas de uma empresa, ao contrário da função do poder disciplinar ao conformar os sujeitos ao ambiente das fábricas por meio da submissão e da repressão de ideias próprias, na lógica do "siga o modelo", sustentada pela venda da força de trabalho por um determinado tempo. Para maximizar o capital humano são utilizadas práticas de governamento mais sutis, "apelando para o convencimento e mostrando os benefícios de ser e agir de um determinado modo" (ibidem., p. 64).

A ideia de permanente mudança é incorporada nas atividades cotidianas objetivando conformar o sujeito aos ditames mercadológicos. A interrupção de um emprego, por exemplo, deve ser encarada como uma mudança positiva pelo sujeito flexível, pois é um convite para novos desafios. Tais mecanismos de convencimento fazem parte de estratégias para o empoderamento pessoal, para potencializar a capacidade de "acessar novos lugares" (Ibidem., p. 65). As subjetividades forjadas pelo capital humano se dão pelos saberes e desenvolvimento de habilidades, no entanto, o foco não está somente em conhecer, mas sim em tornar-se.

No interior deste panorama, o campo da Educação pode ser considerado como uma das principais extensões do mercado a outros aspectos do social, tem sido reorganizado discursivamente segundo a lógica mercadológica, ocorrendo, assim, "uma reestruturação mais sutil das práticas discursivas da educação [...] por tipos de discursos vindos de seu exterior" (PETERS, 1994, p. 213). Ou seja, discursos externos à Educação passam a dar sentido às práticas pedagógicas atuais, reestruturando e potencializado uma série de regimes de verdade.

Assim, a instituição escolar que agora transita entre a composição escola/empresa, continua sendo um locus de produção de sujeitos, mas com a apropriação de um sujeito flexível, tolerante e autônomo, o qual exigem as novas modulações de controle estabelecidas pelo governamento neoliberal. Com a minuciosa observação feita por Foucault e posteriormente por 
seus comentadores no campo da Educação, atentamos que o sujeito que substituirá, gradativamente na escola, o da disciplina é um sujeito marcado pela flexibilidade do mercado, auto empreendedor e produtor de um "capital humano".

Abrimos aqui um parêntese para descrever algumas das características do sujeito empreendedor do seu próprio capital humano potencializadas pelo discurso educacional. As Revistas analisadas ilustram uma série de adjetivos necessários à movimentação do sujeito contemporâneo, seja em relação ao professor que se deseja produzir, ou às identidades individuais e coletivas dos estudantes exigidas pelo ethos neoliberal. Nesse sentido, como o ensino de matemática poderia contribuir para a concepção desta forma-sujeito?

A postura de Luciane revela uma mudança interessante e promove um ambiente em que há segurança para falar sobre estratégias usadas. "Hoje, eles estão mais seguros para explicar o caminho percorrido na solução de problemas. Essa confiança vem sendo construída dia a dia", reconhece (NE, n. 259, 2013, p. 56) [Grifos nossos].

Se tomarmos um depoimento de Paulo Freire durante o VIII Congresso Internacional de Educação Matemática, vamos confirmar que um ensino mais criativo, menos centrado no lado procedimental, é mais democrático e produz cidadãos mais críticos, indagadores e autônomos (NE, n. 148, 2001, p. 54) [Grifos nossos].

Levar o estudante a descobrir esse saber frente a uma situação-problema é o que Katia Smole chama de "desenvolver poder de decisão" (NE, n. 173, 2004, p. 42) [Grifos nossos].

A matemática pode dar sua contribuição à formação do cidadão ao desenvolver metodologias que enfatizem a construção de estratégias, a comprovação e a justificativa de resultados, a criatividade, a iniciativa pessoal, o trabalho coletivo e a autonomia advinda da confiança na própria capacidade para enfrentar desafios (NE, edição PCN, 2000, p. 57) [Grifos nossos].

A Matemática é importante porque dá ao aluno condições de interpretar situações cotidianas, permitindo que ele se insira no contexto sociocultural e no mercado de trabalho desenvolve a capacidade de argumentar, fazer conjecturas, propor mudanças ao trabalhar com a resolução de problemas, contanto que sejam problemas ligados à realidade do aluno, desenvolve nele a criatividade e a crítica, estimulando o espírito de investigação e de pesquisa e tornando-o mais autônomo e ousado (NE, n. 148, 2001, p. 55) [Grifos nossos].

Não se trata de oferecer estratégias prontas para os alunos encaixarem de acordo com os problemas que tiverem de enfrentar, mas estimular que desenvolvam os próprios mecanismos para trilhar caminhos seguros, 
inteligentes e autônomos na resolução de questões matemáticas (NE, n. 233, 2010, p. 82) [Grifos nossos].

Observamos que por meio de práticas pedagógicas no ensino de matemática, os professores objetivam produzir algumas subjetividades que atravessam diversas adjetivações, dentre elas aparece com recorrência a autonomia e a criticidade para enfrentar desafios. Aliado a isso, o estudante deve ser seguro e confiante, estando assim, preparado para tomar decisões, e sabendo argumentar quando necessário. Exige-se, portanto, um sujeito criativo, ousado com iniciativa frente aos desafios impostos pelo professor, o que, com efeito, implica na constituição de novas identidades.

Certamente a viabilidade do neoliberalismo enquanto referencial de inteligibilidade se expandiu desde a análise de Foucault em sua época, pois hoje temos ainda mais elementos para pensar o presente a partir desta racionalidade. No entanto, nossa análise salienta que tais racionalidades ainda coexistem com outras, de caráter disciplinar, que marcam as relações em alguns âmbitos da sociedade, sobretudo na escola. Pelos aspectos disciplinares que ainda carrega, supomos que a escola ensaia incursões nesta nova lógica social, e para a concretização de seus objetivos, conta com uma importante aliada: a Educação Matemática.

Assim, nosso questionamento volta-se às práticas de memorização no ensino de matemática e possíveis entrelaçamentos com essas teorizações, visto que os discursos nesse campo de saber também adquirem espessura em meio ao novo cenário social mobilizado pelo ethos neoliberal.

\section{As práticas de memorização e a constituição do sujeito neoliberal}

Neste estudo engendramos uma investigação que nos permite observar relações de poder emergentes nas tramas escolares, argumentando que a escola está imersa em um tipo de sociedade com caraterísticas singulares de seu tempo, especificamente a partir da discussão sobre o neoliberalismo. Este cenário oferece condições de emergência para diferentes enunciados também no campo da Educação Matemática. Verdades que pareciam naturalizadas agora passam a ser problematizadas nas Revistas. Podemos compreender tais mudanças vinculadas à apropriação do conhecimento matemático, mas, sobretudo, à constituição de outro sujeito, aquele flexível, necessário ao neoliberalismo, em que a memória adquire outros significados. 
Nesse contexto, conforme as enunciações identificadas nas Revistas, o professor de matemática seria estimulado a deixar de lado aqueles exercícios repetitivos e cansativos. Ao contrário, ele apostaria nas situações que gerassem dúvidas, que levassem o aluno a construir hipóteses, tirar suas próprias conclusões, além de elaborar diferentes estratégias de pensamento. Existem diversas estratégias para resolver um problema; cada aluno tem o seu tempo para pensar matematicamente; o erro faz parte do processo construtivo da matemática; a dúvida é fundamental no processo de aprendizagem: são enunciados que foram ganhando força no discurso da Educação Matemática e se entrelaçam àquele que afirma "a memorização mecânica não é eficaz". Tais excertos exemplificam tais enunciados:

[...] o aluno deve não só ser capaz de repetir ou refazer, mas também de ressignificar diante de novas situações, adaptando e transferindo seu conhecimento para resolver desafios (NE, n. 216, 2008, p. 64-65) [Grifos nossos].

Não se deve exigir, portanto, que toda a classe raciocine da mesma maneira para chegar à solução de um problema. Outra característica natural da mente é o questionamento, a busca do novo. A mente nunca está satisfeita. Assim que atinge um objetivo, logo procura outro desafio, cada vez mais difícil de conquistar. Esses processos naturais de aprendizagem constante podem ser interrompidos se o educador passa a dizer aos alunos o que (e como) eles devem pensar (NE, n. 134, 2000, p. 13) [Grifos nossos].

Que críticas podem ser feitas a esse ensino baseado na recitação? O maior problema é que, se o professor informa de antemão aquilo que deseja ouvir, os alunos não constroem o conhecimento e não falam por si próprios, apenas citam e repetem o docente. Há estudantes que se apropriam do que ele fala e avançam, mas há outros que se preocupam somente em se lembrar do que disse (NE, n. 228, 2009, p. 30) [Grifos nossos].

Você deve deixar claro que o resultado de uma multiplicação pode ser obtido por meio de outra. Ter isso em mente é essencial para reforçar que não é necessário decorar a tabuada mecanicamente, mas construir diferentes recursos de cálculo aproveitando o que já se conhece. (NE, n. 248, 2011, p. 40-41) [Grifos nossos].

Existem algumas justificativas que embasam o enunciado que diz respeito à importância da criação de estratégias próprias para resolução de problemas. Os alunos adquirem confiança para resolver os desafios quando não repetem somente o que o professor propõe, mas se apropriam de outros modos de aquisição do conhecimento matemático que se tornam desafios. Nesse sentido, cada sujeito na sua individualidade teria capacidade de buscar soluções criativas de acordo com suas experiências, assim, não cabe ao professor determinar "como o aluno deve 
pensar", ele deve "pensar por si próprio". Tal aspecto parece atravessar outros âmbitos da vida dos sujeitos:

Passamos, assim, de uma cultura da dependência e da execução de tarefas para uma cultura da interação e da resolução de problemas. [...] As respostas já não existem, vivemos novos conflitos, as respostas devem ser construídas. Diante das novas ferramentas, é esta a demanda que nos espera: não apenas repetir, mas expressar, interpretar, pensar e, também compartilhar (MOSÉ, 2013, p. $55)$.

Esse fato nos leva a identificar, nas enunciações, os sujeitos que se intencionam produzir, nas características que são próprias de um sujeito necessário ao neoliberalismo, compreendendo as práticas de memorização como movimentos sutis que contribuem para sua constituição. Atentando a essas características, elencamos nos excertos abaixo os principais atributos esperados dos alunos, por serem os mais recorrentes quando se trata da crítica aos processos mecânicos no ensino de matemática:

A molecada sistematiza um conjunto de procedimentos, constrói um pessoal e consegue decidir, em outras situações, pelo mais eficaz. [...] A ideia é que a criança tenha cada vez mais recursos para chegar ao resultado das operações com segurança, de maneira progressivamente econômica e, acima de tudo, compreendendo a resolução (NE, n. 201, 2007, p. 64) [Grifos nossos].

Ao contrário do que diz o tabu, é possível, sim, criar questões que gerem dúvidas. Tudo depende do aluno que se quer formar. Você quer que seu aluno seja no futuro um indivíduo passivo, que aceita cabisbaixo tudo o que the apresentam, ou alguém crítico, que propõe hipóteses e tira as próprias conclusões? Se for esse o caso, não traga respostas prontas (NE, n. 160, 2003, p. 44) [Grifos nossos].

Apenas uma parcela do que se ensina hoje ajuda as crianças a ser autônomas. Todo o resto são palavras que parecem não servir para nada, que não fazem sentido para os estudantes. Decoramos tudo isso porque somos coagidos, ficamos com medo de receber uma nota ruim ou de reprovar (NE, n. 284, 2015, p. 15) [Grifos nossos].

Os registros devem ser colocados nos cadernos e à vista de toda a turma para servir de material de consulta. A intenção deve ser ampliar o repertório de produtos memorizados pelos estudantes para que eles tenham autonomia para resolver problemas (NE, n. 248, 2011, p. 43) [Grifos nossos].

[...] o importante é que, por intermédio dos jogos, a tabuada torna-se um desafio permanente ao raciocínio das crianças e também uma conquista pessoal baseada no interesse de participar grupalmente. Neste aspecto, o que não tinha utilidade passa a ser palpitante aos olhos dos alunos. E as relações de confronto verbal provocadas pela competição desenvolvem o senso de ordem e justiça. [...] esta mudança no enfoque da multiplicação a torna bem mais prazerosa (NE, n. 44, 1990, p. 26) [Grifos nossos]. 
Como lidar com números sem dor nem trauma para a criançada. [...] "Não damos nada pronto para o aluno. Trabalhamos junto com ele na construção do conhecimento. A partir daí, ele se torna independente, questiona, decide e analisa as questões colocadas" (NE, n. 57, 1992, p. 27) [Grifos nossos].

Ao longo das reportagens é possível perceber que a lógica que sustenta as práticas pedagógicas desses professores está alicerçada no anseio de formar sujeitos mais críticos, autônomos, indagadores e ousados. O ensino deve estar centrado na criatividade e no poder de decisão, não em procedimentos e respostas dadas como prontas, afirmam as reportagens. Não defenderem a decoreba, mas a criação de estratégias próprias em que os alunos são protagonistas de seu aprendizado. Outros atributos aparecem nas enunciações como a iniciativa, a confiança em si, a segurança, a independência, a capacidade de lidar com novos desafios, que refletem algumas ambições da escola em nosso tempo, que não seriam possíveis por meio de um ensino com ênfase na memorização mecânica, afirmam as reportagens. Trazer respostas prontas em que o aluno só precisa memorizar seria uma condição contrária aos moldes deformantes das novas orientações pedagógicas que reforçam o poder criativo das crianças e dos jovens, já que não poderiam "tirar suas próprias conclusões" sobre o saber nem estariam desenvolvendo o espírito investigativo.

Desta maneira, a autonomia parece ser uma das premissas que sustentam os enunciados sobre a memorização nesta nova lógica: ora esta prática é útil para liberar os alunos para resolverem problemas matemáticos em que possam desenvolver todas estas habilidades; ora a memorização é condenada por ser um procedimento mecânico que inibiria tais atitudes autônomas. De todo modo, as práticas acabam se ajustando aos mecanismos de funcionamento da escola-empresa em que uma das condições necessárias é o desenvolvimento da autonomia dos estudantes.

A matemática, em conformidade com os discursos educacionais de nosso tempo, deve ser ensinada de modo a formar um sujeito criativo, produtor de ideias inovadoras e crítico sobre suas escolhas na escola e na vida. No entanto, o professor Ubiratan D’Ambrósio, em uma entrevista concedida à Revista n. 68 em 1993, afirma que esta disciplina, por décadas, foi responsável por “emburrecer" os estudantes, dificultando o processo de subjetivação a que são submetidos hoje por meio da criatividade exercitada na escola. Um aluno com boas notas em matemática talvez faça parte do modelo repetitivo de ensino que se disseminou por décadas e que colocou barreiras no desenvolvimento da capacidade criativa dos alunos, segundo 
D’Ambrósio. Nesse sentido, a Etnomatemática, conforme ele aponta, tornou-se uma saída para estimular a criatividade pela Educação Matemática. Destacamos ainda outras enunciações que dão ênfase à importância do poder criativo:

Ubiratan - [...] Na Etnomatemática, a gente tem claro que o fato de uma criança não saber fazer uma continha não significa que ela não seja criativa, mesmo porque não há criatividade alguma em saber fazer continhas. (NE, n. 68, 1993, p. 14) [Grifos nossos].

Com as mudanças tecnológicas e sociais do mundo contemporâneo, estimular o lado criativo das pessoas passou a ser vital e a escola acabou vista como uma das principais responsáveis por esse trabalho. "Estar preparado para solucionar problemas de forma criativa é algo indispensável no cenário deste novo milênio, em que inovar é uma palavra e ordem" acredita Eunice (NE, n. 218, 2008, p. 49-50) [Grifos nossos].

É assim que não se faz: Outra fórmula certeira de inibir a criatividade de seus alunos é dar ênfase ao "é assim que se faz" ou ao "siga o modelo". Ao contrário, estimule-os a explorar e pensar um pouco mais sobre as questões (NE, n. 81, 1994, p. 81) [Grifos nossos].

O conhecimento lógico-matemático pode ser ensinado pelos educadores? Constance: Isso não é algo que se ensina tradicionalmente, porque a fonte dele é a própria cabeça do aluno. Os professores precisam oferecer oportunidades para que as crianças pensem por si sós, raciocinem, e aí construam esses saberes (NE, n. 284, 2015, p. 14) [Grifos nossos].

A criatividade exercitada nas aulas de matemática é uma premissa bastante defendida nas edições da Revista, conforme a análise realizada, pois “inovar é uma palavra de ordem” em todos os âmbitos da vida do sujeito. Como afirma uma professora em 2008, a criatividade é inata ao ser humano, e a Educação tem o papel de desenvolvê-la. Principalmente a partir da década de 1980 esse discurso adquire força, segundo ela, devido às mudanças tecnológicas. É fundamental observarmos que a criatividade aparece associada às características do sujeito empreendedor de si, como a autonomia, a ousadia e a criticidade. Além disso, esta verdade justifica-se pela criação de diferentes maneiras para resolução de um problema matemático.

Tais reconfigurações observadas pelo entrelaçamento de enunciados acabam produzindo outros modos de subjetivação na contemporaneidade e novas técnicas de captura são inventadas, ou em termos foucaultianos, outra governamentalidade é instituída, que especialmente "mobiliza as pessoas de forma que elas se tornem "empresários de si", respondendo pela rentabilidade de seu trabalho e vendo-se a si mesmas como uma empresa" (SARAIVA, 2015, p. 64). Portanto, podemos dizer que o anseio por promover a criatividade, 
advindo dos docentes, decorre também das rápidas e generalizadas mudanças pelas quais a escola contemporânea vem passando. Do mesmo modo, esta instituição é responsável por fabricar um sujeito criativo, desejável ao ethos neoliberal em que a criatividade se torna um adjetivo requisitado.

Podemos inferir que a Educação Matemática a partir destas práticas, não pretende mais produzir alunos dóceis que realizam as atividades de forma mecanizada conforme a exigência das fábricas e dos mecanismos disciplinares. A necessidade agora, é que de sujeitos flexíveis dentro da lógica da empresa, em que a matemática não é mais um instrumento de dominação, mas um elemento fundamental para privilegiar a autonomia e a criatividade dos educandos. Em síntese, dentre as competências que se esperam do sujeito contemporâneo observamos a necessidade de "produzir, em vez de apenas memorizar conhecimento; criar, em vez de apenas reproduzir valores; abrir novos mercados em vez de se enquadrar no existente" (MOSÉ, 2013, p 31).

Nesse contexto, o capitalismo cognitivo assume o lugar do capitalismo industrial, a produção de ideias e de bens imateriais, o lugar da produção material, como afirma Saraiva (2015). A produção em massa pela fábrica desloca-se para a produção de ideias inovadoras e criativas pela empresa, em outras palavras, não importa tanto a força do corpo, mas a potência do cérebro. Segundo a autora (2012, p. 139), nesta racionalidade "o trabalho perde parte de suas características fortemente disciplinares, para tornar-se algo que exige mais do que um corpo treinado: agora é necessário ter um cérebro flexível, empreendedor, criativo". Nesta esfera, o professor não deve apresentar respostas prontas a serem memorizadas e caminhos já determinados, pois os sujeitos contemporâneos "procuram consultores que os ensinem a caminhar, e não professores que os orientem num percurso único e já superlotado" (BAUMAN, 2010, p. 54).

\section{Considerações Finais}

Nesse estudo buscamos mostrar, a partir das enunciações identificadas nas edições da Revista Nova Escola, que certas práticas pedagógicas acabam, mesmo que de forma sutil, corroborando para a constituição do sujeito neoliberal. Constatamos que ao negarem a memorização mecanizada e o ensino tradicional da matemática, as reportagens enfatizam a formação de um aluno crítico, que se adeque a novas situações e saiba resolver novos desafios com segurança. Independência e autonomia ao raciocinar matematicamente produzem um 
estudante criativo e inventor do seu próprio processo de aprendizagem. Estas são características que aparecem como justificativas para que o ensino desta disciplina não se baseie somente em decorar fórmulas, regras e algoritmos, afinal, o aluno não deve somente reproduzir aquilo que é transmitido pelo professor.

Para esta reflexão, as teorizações foucaultianas nos auxiliaram na tarefa de problematizar verdades como aquela que afirma: "Hoje não é mais necessário que o aluno memorize conteúdos matemáticos", e as relações de poder presentes nessas práticas. Para além de considerar os diferentes traços do poder como bons ou ruins, Foucault buscou localizar as positividades e igualmente possíveis perigos que nos permitiriam indagar sobre oportunidades de resistência crítica a tais poderes. Suas teorizações não se comprometeram com questões transformativas no sentido de revoluções. Estudiosos de suas obras consideram esse ponto um "dilema" na obra de Foucault, como afirma Rajchman (1987, p. 46):

o seu método de análise histórica profunda coloca-o numa posição intelectual sem reforma ou revolução para recomendar. E, no entanto, ele estava intelectualmente propenso a ver sua obra como uma contribuição para as lutas políticas de esquerda! É a isso que chamo o dilema de Foucault.

Da mesma forma, podemos dizer que não tivemos a intenção de ocupar uma posição que atribuísse juízo de valor fazendo, por exemplo, uma análise moral das práticas utilizadas pelos professores como apontadas nos exemplares da Revista. Seguindo as pistas foucaultianas, entendemos que "o genealogista é um imoralista. O moralista diz: "deves". O imoralista pergunta: “quem diz que deve?”. O moralista pretende atribuir a opção por determinados a um universal "nós”. O imoralista pergunta “nós quem?”” (CORAZZA; SILVA, 2003, p. 46).

Buscando uma aproximação com as ferramentas foucaultianas, não recorremos à tentativa de formular reflexões que deveriam ser seguidas pelos professores, de criar modelos de práticas para um ensino mais eficaz por meio da memorização, ou colocar reflexões melhores no lugar das antigas. Acreditamos que os trabalhos realizados na perspectiva da sugestão de novas metodologias e didáticas apresentam contribuições para o campo da Educação Matemática. No entanto, nosso empreendimento visa mobilizar uma reflexão que desafie o professor a repensar sua experiência docente a partir de pontos que talvez não tenham sido percebidos.

Este estudo nos possibilita, por outro lado, atentar as mais diversas formas com que os ideias neoliberais se instauram na sociedade. Knijnik (2016), por exemplo, indica como esta lógica empresarial afeta nossos modos de vida e convivências diárias. Um dos aspectos do 
contexto neoliberal apontado pela autora é a lógica do individualismo, imbricada à competição, em que os indivíduos se veem como adversários que tendem a superar as qualidades do outro:

[...] nos tempos atuais, a grande competição que está em jogo é a competição por consumidores... E, é claro, nas universidades e nas escolas, em nossas instituições de pesquisa, em órgãos como a CAPES e o CNPq, por toda parte, é também essa lógica da competição que está em jogo. Somos capturados pelo desejo de competir... de sermos melhores que "o outro", nossos estudantes melhores que outros estudantes, nós mesmos melhores que os outros pesquisadores, nossos programas de pós-graduação melhores que os outros programas (KNIJNIK, 2016, p. 11).

Diante deste cenário "perigoso", pelo qual somos capturados instantaneamente, cabenos criar estratégias de resistência. Ao constatar a positividade do poder e da capilaridade do governo não negamos que algo possa ser feito por meio das lutas diárias em torno das relações que permeiam as práticas cotidianas. Considerar o neoliberalismo, por exemplo, "como um instrumento que abre caminho para uma reflexão sobre nós mesmo não significa, naturalmente, considerá-lo um dado, uma evidência, um fenômeno cuja realidade e cujas características teríamos de aceitar passivamente" (LAGASNERIE, 2013, p. 28).

$\mathrm{Na}$ perspectiva foucaultiana, as lutas em torno do poder caracterizam-se como resistências ou contracondutas, pois seu fluxo é contrário aos procedimentos revolucionários e predominantes. Foucault (2012) sugere que devemos originar nossas próprias revoluções ao contestar e transformar os sistemas que ordenam a sociedade de forma pacífica. Portanto, concluímos esta reflexão com os seguintes questionamentos: Como poderíamos mobilizar contracondutas a partir de nossas armas na Educação? Ou mais especificamente, como a Educação Matemática poderia promover modos de resistência aos poderes e às formas de governo como o neoliberalismo?

\section{Referências}

AQUINO, Julio Grappa. Pedagogização do pedagógico: sobre o jogo do expert no governamento docente. Educação, v. 36, n. 2, 2013.

BAUMAN, Zygmunt. Capitalismo parasitário: e outros temas contemporâneos. Tradução de Eliana Aguiar. Rio de Janeiro: Zahar, 2010.

CORAZZA, Sandra; DA SILVA, Tomaz Tadeu. Composições. Autêntica Editora, 2003.

DUARTE, Claudia Glavam. A "realidade” nas tramas discursivas da educação matemática escolar. 2009. Tese (Doutorado em Educação) Programa de Pós-Graduação em Educação, Universidade do Vale do Rio dos Sinos, São Leopoldo, 2009. 
FOUCAULT, Michel. A arqueologia do saber. Tradução de Luiz Felipe Baeta Neves, -7ed. Rio de Janeiro: Forense Universitária, 2008a.

FOUCAULT, Michel. Nascimento da Biopolítica: curso dado no Collège de France (19781979). Martins Fontes, 2008b.

FOUCAULT, Michel. Ditos e Escritos, volume IV: estratégia, poder saber. Rio de Janeiro: Forense Universitária, 2012.

KNIJNIK, Gelsa. Pesquisar em Educação Matemática na contemporaneidade: perspectivas e desafios. In: Jornal Internacional de Estudos em Educação Matemática, v. 9, n. 3, p. 1-14, 2016.

LAGASNERIE, Geoffroy. A última lição de Michel Foucault. São Paulo: Ed. Três Estrelas, 2013.

MOSÉ, Viviane. A escola e os desafios contemporâneos. $2^{\mathrm{a}}$ ed. Rio de Janeiro: Civilização Brasileira, 2013.

PETERS, Michael. Governamentalidade Neoliberal e Educação. In: SILVA, Tomaz Tadeu da. (orgs). O sujeito da educação: estudos foucaultianos. Petrópolis, RJ: Vozes, 1994.

RAJCHMAN, John. A política da revolta. In: RAJCHMAN, John. Foucault, a Liberdade da filosofia. Trad. Álvaro Cabral. Rio de Janeiro: Jorge Zahar Editora, 1987.

SARAIVA, Karla. Aprender Matemática para desenvolver o Brasil. Revista Reflexão e Ação, Santa Cruz do Sul, v.20, n2, p.136-153, jul./dez. 2012.

SARAIVA, Karla. Novas geometrias no trabalho e na educação. In: Estudos Culturais e Educação: contingências, articulações, aventuras, dispersões, p. 57-72, 2015.

VEIGA-NETO, Alfredo. Educação e governamentalidade neoliberal: novos dispositivos, novas subjetividades. Retratos de Foucault. Rio de Janeiro: Nau, p. 179-217, 2000. 